\title{
7 Women and gender-related aspects
}

\author{
Stefano Borgato, Silvia Maffi, \\ Patrizia Malgieri and Cosimo Chiffi
}

\begin{abstract}
Every day, many women struggle to access essential opportunities such as jobs, education, shops and friends. Failing to provide them with adequate transport services can eventually lead to an undesirable situation of social disadvantage and exacerbate the gender gap between men and women. This chapter explains how being a woman has a significant influence on mobility characteristics and travel behaviour. It also goes deeper into the main challenges and issues that need to be overcome to reduce inequalities of access and movement opportunities between genders. Properly addressing these challenges plays a crucial role in providing women with empowerment, access to opportunities and independence.
\end{abstract}

\section{Introduction}

When we talk about women in transportation, we are not talking about a specific group of vulnerable users. We are talking about half of the world's population. Therefore, it is fundamental to always adopt a gender-sensitive perspective when considering the particular mobility needs of people and more specifically of other vulnerable demographic groups, be they on low income, elderly, migrants, or people living in rural areas. In fact, half of these people are also women and this situation will eventually further affect the way in which they will be able to access, exploit and utilise transport services.

Recent research demonstrates that gender is one of the key factors in accounting for differences in mobility and travel behaviour, together with other important socio-demographic variables (income, household composition) as well as access to means of transport (both private and public), infrastructures and services (Peters 2013). However, it is often the least understood socio-demographic variable.

As will be highlighted in the following paragraphs, there are some significant differences between the two genders that need to be taken into account when discussing gender-related mobility. In particular, integrating gender 
means taking into account the different requirements and needs associated with the different genders. The concept of gender equality refers to the aim of reducing inequalities of access and opportunities between men and women (Duchène 2011).

As transport is a means to improve the well-being of people, by facilitating their access to economic and social benefits, it should be designed as equitable, affordable and responsive to all groups as possible (ADB 2013). This implies that a greater gender sensibility should be considered in mobility analysis, planning and practice (Peters 2013, CIVITAS 2014) and in designing transport policies which are often incorrectly considered as "gender neutral" (ADB 2013, Chadha and Ramprasad 2017).

However, while greater account is being taken of gender in a variety of areas, little progress has been made in this respect in the transport sector. In both the international body of literature and transport planning, the gender dimension in mobility patterns has received little attention so far, even though gender is considered a significant factor in accounting for differences in mobility behaviour. As a consequence, relevant and systematic statistical information is often not available, thus inhibiting gaining an understanding of travel practice differentiated by gender (Duchène 2011).

Most of the transport planning and policy-making all over the world are still influenced by transport planning standards, procedures and methodologies developed in industrialised countries over the course of the last century and based implicitly or explicitly on the assumption that households typically consisted of nuclear families with a traditional division of labour, i.e. a male 'breadwinner' with primary responsibility for the 'productive' tasks within the household and a female 'housewife' with primary responsibility for the 'reproductive' caretaking tasks (Sheller 2008).

In more recent decades, the evolution of household and parental models together with new developments in the labour market and new technologies with the spread of new forms of work have determined a change in the role of women in society. Women have increased their participation in the labour market, though gaps are still far from overcome. So, to some extent the travel behaviour trends of women and men are slowly converging, in particular regarding the possession of a driving licence.

However, significant differences still remain due to the different role of women and men in the in the household and the fact that women have lower employment rates, the majority of part-time roles and low-wage positions. As a consequence, women have far more complex activity schedules: household chores and childcare require a higher degree of synchronisation, planning and coordination with multiple external factors. In other words, these mobility needs require a greater effort in order to be addressed.

Clarifying female (and male) mobility trends and patterns should help understand the persistence of gender roles, which is necessary for policymakers to better target directives aimed at addressing women's mobility challenges (McGuckin and Nakamoto 2004). 


\section{Socio-demographic characteristics}

As outlined in the introduction, women represent a very large vulnerable group as they account for $51 \%$ of the total European population. Therefore, when we discuss gender transportation challenges, we are talking about an issue that affects more than half of Europe's citizens. Indeed, there are some significant differences in terms of socio-demographic characteristics between males and females that is worth mentioning in order to better comprehend women's transportation behaviour and mobility challenges.

Notably, women leave their parental home earlier than men (around two years earlier) and get married earlier (between three and two years earlier). In addition, women live longer than men, with an average 5.4 years difference in 2016 (Eurostat 2018a).

As a result of a longer life expectancy, there are more women than men in the EU, with 105 women per 100 men in 2017 (Eurostat 2018a). The biggest differences can be seen in Latvia (18\% more), Lithuania (17\% more) and Estonia (13\% more), while Luxembourg, Malta and Sweden have slightly more men than women (Eurostat 2018a). Looking at young people aged up to 18, the opposite pattern applies with 5\% more young men than young women of this age. On the other hand, among the older group aged 65 and over, there are $33 \%$ more women (Eurostat 2018a).

Other differences can be observed considering household compositions. In 2017 in the EU, around 8\% of women aged 25-49 lived alone with children, compared with $1.1 \%$ of men of the same age. For singles without children in this age group, the percentage was $9.6 \%$ for women and $16.3 \%$ for men. Another group with large differences between men and women is for singles aged 65 and over: the percentage of elderly women living alone $(40.4 \%)$ was twice the percentage for men $(19.9 \%)$ (Eurostat 2018a).

When looking at the level of education completed, there are hardly any differences between women and men in the EU at lower education level. However, different patterns can be seen at the higher levels. Specifically, there is a majority of women (33\% versus 30\%) who have completed the tertiary level of education in almost all Member States (Eurostat 2018a).

On average, the employment rate of men is higher than that of women ( $73 \%$ compared with $62 \%$ in the EU in 2017). However, this difference increases with the number of children. The employment rate for women without children is $66 \%$, while it is $74 \%$ for men. For women with one child, the rates increase and are $71 \%$ for women and $86 \%$ for men. For women with two children, the rate remains almost the same at $72 \%$, while the one for men increases to $90 \%$. Finally, for those with three or more children, the employment rate drops to $57 \%$ for women, compared to $85 \%$ for men (Eurostat 2018a). 
The principal reasons behind this employment gap may be (Eurostat 2018b):

- Labour market issues, including employers preferring to hire young men over young women; young women facing assimilation difficulties when returning to work after childbirth; young women being more likely to have low-paid jobs or precarious employment.

- The way the family work and childcare is currently divided between parents, with a great majority of females undertaking such activities.

- Social conventions, which tend to place a higher importance on women's role within the family.

- Education and careers advice, which often reinforce gender segregation and direct women into a relatively narrow range of occupations.

In addition, an important aspect of the reconciliation between work and family life is part-time work. However, this is not equally divided between women and men. 32\% of women in employment work part-time, compared with $9 \%$ of men. The highest share of women working part-time is in the Netherlands (74\%), while the lowest is observed in Bulgaria (2\%) (Eurostat 2018a). Also, the female/male unemployment rates show some differences between the Member States, but the EU average is very close (7.9\% for women versus 7.4 for men) (Eurostat 2018a).

In terms of earnings, women earn $16.2 \%$ less than men when comparing their average gross hourly earnings, giving an overall picture of gender inequalities in terms of hourly pay. That said, this pay gap is linked to a number of cultural, legal, social and economic factors which go far beyond the single issue of equal pay for equal work (Eurostat 2018a).

Finally, for all Member States, there is a much larger share of women undertaking child care, housework and cooking than men. $92 \%$ of women aged 25 to 49 (with children under 18) take care of their children on a daily basis, compared with $68 \%$ of men. The largest differences are observed in Greece (95\% of women versus $53 \%$ of men) and Malta (93\% and 56\%, respectively), while the smallest are in Sweden (96\% of women and $90 \%$ of men) and Slovenia (88\% and 82\%, respectively) (Eurostat 2018a).

\section{Gender differences in travel patterns}

Gender is an important factor in accounting for notable differences in mobility and travel behaviour. Since women and men experience transport differently, as they use different modes for different purposes and in different ways, they also have different preferences and constraints.

Recognition of the existing links between gender and mobility has only recently begun to emerge in literature. One of the reasons is the lack of gender-differentiated statistics that makes it difficult to understand gender differences in relation to reasons for making journeys, journey frequencies, 
distance travelled and mobility-related problems in accessing services and employment.

That said, it is possible to affirm that the major differences in the basic mobility needs of women and men are grounded in the different social roles they play and in the gender-based division of labour within the family and the community (CIVITAS 2014).

Statistics show that women spend more than two thirds of their time at home. They also usually have less free time than men, being engaged in childcare, domestic work and caring for elderly, sick or disabled relatives. Therefore, women are more likely to work part-time, to choose jobs that are nearer or better connected to home (even if low-paid) or to decide not to work at all (Eurostat 2018a).

A review of the literature showed significant gender differences in terms of frequency, time, mode and purpose of travel (Hasson and Polevoy 2011, Schwanen 2011, Hodgson 2012, Samek Lodovici et al. 2012, CIVITAS 2014, Department for Transport 2014, Tilley and Houston 2016).

In particular, these studies have indicated that women with respect to men tend to:

- Have shorter commutes;

- Have a shorter distribution of travel during the day and less concentrated during peak hours;

- Transform chain trips into complex journeys to conduct householdserving trips more often; and

- Make less use of the car and more of public transportation.

On average, women commute shorter than men in both distance and time due to lower incomes, available modes of transport, occupation status, location choice, socio-economic factors, geographical structure and infrastructure availability.

In general, women face greater time-space constraints in commuting. In 2015, in the EU the share of male and female outbound commuters among all employed persons was systematically higher for men compared to women in each of the member states for which data were available (Eurostat 2018b).

In addition, while on average women tend to travel less for work (and these differences tend to increase together with the gender disparities in labour market participation), they travel more frequently for the purposes of shopping, escorting family members and household management (CIVITAS 2014) (Figure 7.1).

In terms of mode choice, there is a gender difference in relation to the utilisation of different transport modes (European Commission 2013). In fact, a higher proportion of men travel by car and motorcycle, while women walk, bike and use public transport more than men.

Men are more likely than women to use a car daily (57\% versus $42 \%$ at EU level) (European Commission 2013). On the other hand, women tend to 


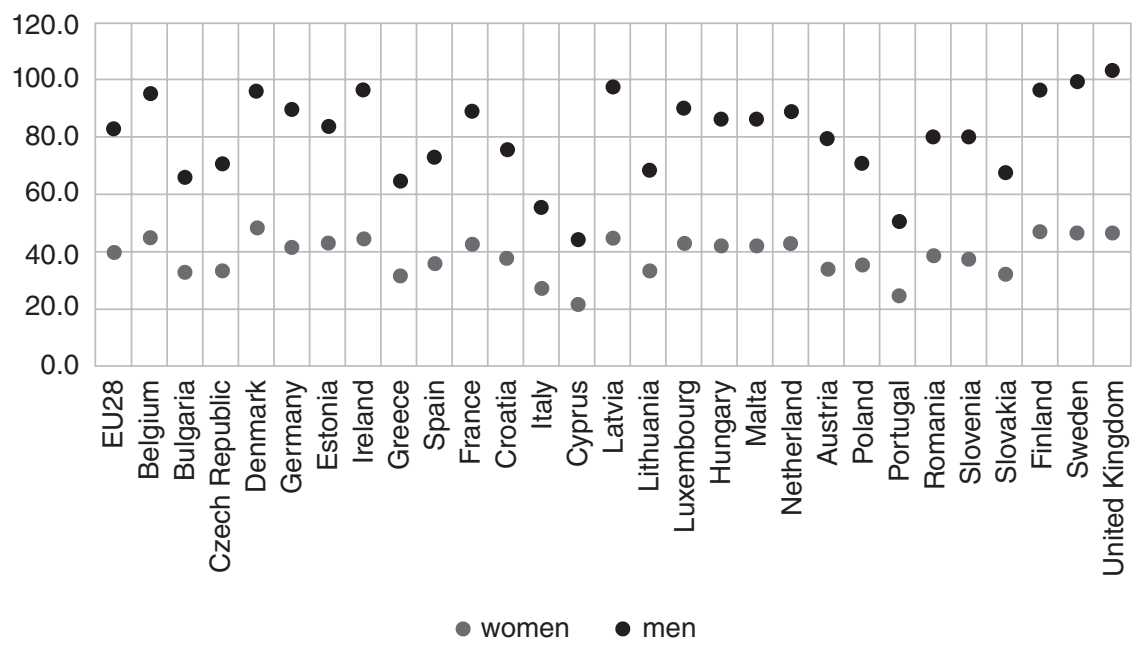

Figure 7.1 Average duration of commuting time one-way between work and home by gender (15-64), 2015.

Source: Eurofound 2017.

travel in cars more frequently as passengers rather than as drivers (CIVITAS 2014). Also, women have less access to private cars and driving licences than men for reasons that may be attributed to economic inequality and gender stereotypes. In single car households, the car is normally used by the male partner.

That said, the number of women drivers has been growing between 2000 and 2010 (a 3.5\% increase) (SARTRE 2012) and women's access to a car is increasing almost universally across all age groups (Stokes 2012). The converging patterns are also shown with regard to the possession of a driving licence (Duchène 2011).

While women have lower rates of motorisation than men, they complete a larger share of trips by walking or using the bicycle (Heesch et al. 2012, ). Also, women tend to use public transport more than men (Allen 2018).

Considering shared mobility, several surveys underlined that the regular user of car-sharing and bike-sharing is more likely to be male rather than female (Pickup et al. 2015, Chatterjee et al. 2018).

In terms of older people, researchers indicate that older women's travel patterns and transport choices have been changing as well, reducing differences with older men's patterns (Department for Transport 2009, Su and Bell 2012).

Finally, compared to men, women tend to be more environment-focused as well as hold more positive views of speed limits and congestion fees and 
initiatives geared towards the promotion of a more sustainable transport system (Basarić et al. 2016).

\section{Challenges for women in transportation}

Even if gender mobility patterns have been changing in recent years, reflecting the evolution of gender differences in socioeconomic and demographic conditions (CIVITAS 2014), the analysis of the socio-economic background together with projections and trends confirm that, though narrowing, the gap between genders is still evident and has effects on mobility patterns.

As highlighted in the previous section, differences in participation in the labour market, the employment gap, caring and family duties and education level influence women's mobility patterns and pose a series of challenges in order to satisfy them. Transport is still not gender-neutral and gender needs have to be properly addressed by experts and policymakers (Allen 2018).

It is fundamental to properly address these challenges as transportation access plays a crucial role in empowerment, access to opportunities, social life and independence (Samek Lodovici and Torchio 2015, World Economic Forum 2017). Research shows that poor mobility and access to transport can prevent women from entering the labour market or lead women to choose less profitable jobs because they are closer to home or easier to travel to, even in the case of self-employment (Hanson 2003).

In order to guarantee fair access to transport for both men and women and reduce the disadvantages for the latter, a series of considerations should be taken into account in order to guarantee the quality, safety and comfort measures required by women.

First of all, we should consider that women have generally less access to resources and are economically-disadvantaged regarding the control of the household's finances. Therefore, affordability of transport is especially relevant for them. Constrained access to transport can also exacerbate gendered poverty. Women are likely to take inexpensive and therefore slower modes of transport. Therefore, it is essential to improve the overall conditions for travelling to allow women to meet their needs and aspirations as well (Allen 2018).

As mentioned, women have different travel patterns and use public transport and walking more than men. They make more trip chains and depend more on off-peak and off-branch travel. This needs to be understood and taken into account by removing the barrier that might prevent women from accessing public transport (e.g. many women travel with children and strollers) and by offering more flexible services (Allen 2018).

In this respect, the traditional public transit offer, with schedules concentrated on peak hours to primarily satisfy journey-to-work trips and on high demand links, does not generally fit women's needs and basically disregards the needs of part-time/shift working or non-working people. 
In addition, it is fundamental to take into account the fact that women's modal choice depends not only on the conventional parameters (times, costs and comfort) but also on the conditions and safety of the journey. Women are more affected by safety and security issues as they are more likely to encounter violence and harassment when they are using public space, particularly on public transport. This reduces the freedom of movement of women and girls, and their ability to attend school or work and participate fully in public life.

Failure to take account of women's safety sometimes prompts the latter to prefer private car use to public transport or limit their presence on public transport to certain hours and certain routes that are perceived as safe. A bus user survey conducted in London in 2008 showed that women are far less likely to take a night bus (35\%) than they are to take a day bus $(54 \%)$ (Transport for London 2014). The failure to take into consideration women's safety can encourage them to choose their private car instead, if available, or to forego the trip, if not.

Finally, it has to be taken into account that, considering the current ageing trends - women account for the majority of elderly people - and the higher life expectancy at birth for girls, there will be an increasing number of old women living alone, with significant mobility problems and difficulties in accessing services.

\section{Conclusions}

As women represent half of the world's population and constantly face multiple challenges when it comes to mobility (whether related to inclusion, safety or accessibility), it is fundamental to properly address such difficulties, especially when they are combined with the ones typical of other vulnerable groups (e.g. women living in rural areas, low-income women, female migrants).

Lower employment rates, part-time roles, family care duties, low-wage positions and safety issues are the main factors which determine sensible differences between genders in the labour market, in social life and consequently in transport behaviour. The emerging picture is one where women travel differently than men in relation to transport mode used, distance travelled, the daily number of trips and their pattern and travel purposes (CIVITAS 2014).

In order to reduce women's burden and address their diverse requirements, further study is mandatory to better understand women's mobility. Collecting gender-disaggregated data to understand female travel patterns and conducting gender impact assessments should be the starting point that will eventually encourage planners, policymakers and service managers to embrace gender-responsive policies and develop more inclusive (friendly street network, barrier-free public transport) and safe (public areas with 
visibility, lighting at transit stations, trained transit staff to deal with harassment) mobility environments and services for women.

Mobility and access have to be recognised as essential conditions equally for both women and men to be able to exercise many of their rights, tasks and activities, including access to work, education, social activities and other essential services. It is now time to think about how to really make mobility systems gender-responsive, sustainable and affordable, giving women real choices and access to opportunities that will avoid the social exclusion of women in vulnerable situations and will achieve equity between women and men.

\section{References}

ADB. 2013. "Gender tool kit: Transport maximizing the benefits of improved mobility for all." Asian Development Bank, Mandaluyong City, Philippines. https:// www.adb.org/sites/default/files/institutional-document/33901/files/gender-toolkit-transport.pdf. Accessed 19 March 2020.

Allen, Heather. 2018. "Approaches for Gender Responsive Urban Mobility.” Sustainable Urban Transport Project. Bonn and Eschborn: Deutsche Gesellschaft für Internationale Zusammenarbeit (GIZ) GmbH.

Basarić, Valentina, Jelena Mitrović, Vuk Bogdanović, and Nenad Saulic. 2016. "Gender and age differences in the travel behavior - a Novi Sad case study." In Transportation Research Procedia 14: 4324-4333. https://doi.org/10.1016/j.trpro. 2016.05.354.

Chadha, Jyot, and Vishal Ramprasad. 2017. "Why it is key to include gender equality in transport design.” In The City Fix. https://thecityfix.com/blog/why-it-is-keyto-include-gender-equality-in-transport-design-jyot-chadha-vishal-ramprasad/. Accessed 8 March 2017.

Chatterjee, Kiron, Phil Goodwin, Tim Schwanen, Ben Clark, Juliet Jain, Steve Melia, et al. 2018. "Young people's travel - what's changed and why? Review and analysis." The Centre for Transport \& Society. UWE Bristol, UK. www.gov. uk/government/publications/young-peoples-travel-whats-changed-and-why. Accessed 13 June 2018.

CIVITAS. 2014. "Smart choices for cities - Gender equality and mobility: mind the gap!," CIVITAS WIKI Policy Analyses series. http://www.ricerchetrasporti. it/test/wp-content/uploads/downloads/2014/10/CIVITAS_Second-Policy-Note_ Gender-equality-and-mobility-mind-the-gap.pdf. Accessed 19 March 2020.

Department for Transport. 2009. UK, National household travel survey. Department for Transport. https://www.gov.uk/government/collections/national-travelsurvey-statistics\#publications. Accessed 20 June 2018.

Department for Transport. 2014. National travel survey trip chaining: 2002-2014 (UK Government Factsheet 2014). https:/www.gov.uk/government/uploads/ system/uploads/attachment_data/file/509447/nts-trip-chaining.pdf. Accessed 14 June 2018.

Duchène, Chantal. 2011. "Gender and transport.” OECD/ITF Joint Transport Research Centre Discussion Papers - Discussion Paper No. 2011-11. http://www. oecd-ilibrary.org/docserver/download $/ 5 \mathrm{~kg} 9 \mathrm{mq} 47 \mathrm{w} 59$ wen.pdf?expires $=15030$ 
70935\&id=id\&accname $=$ guest $\&$ checksum $=1841$ AC9F8A1703AF30ADE9A6F 22EF00C. Accessed 19 March 2020.

Eurofound. 2017. 6th European working conditions survey. 2017 update. http:// rhepair.fr/wp-content/uploads/2017/12/2017-Update-6th-European-WorkingConditions-Survey-Eurofound.pdf. Accessed 20 June 2018.

European Commission. 2013. "Attitudes of Europeans towards urban mobility." Special Eurobarometer 406/ Wave EB79.4. http://ec.europa.eu/commfrontoffice/ publicopinion/archives/ebs/ebs_406_en.pdf. Accessed 13 June 2018.

Eurostat. 2018a. "The life of women and men in Europe." https://ec.europa.eu/ eurostat/cache/infographs/womenmen/images/pdf/WomenMenEurope-Digital Publication-2018_en.pdf?lang=en. Accessed 19 March 2020.

Eurostat. 2018b. Database extraction. http://eige.europa.eu/gender-statistics/dgs. Accessed 20 June 2018.

Hanson, Susan. 2003. "Geographical and feminist perspectives on entrepreneurship.” In Geographische Zeitschrift 91, no. 1: 1-23. https://doi.org/10.2307/27818963.

Hasson, Yael, and Marianna Polevoy. 2011. "Gender equality initiatives in transportation policy, a review of the literature." Women's Budget Forum, Heinrich Boell Stiftung, European Union, Hadassah Foundation. https://il.boell.org/sites/ default/files/gender_and_transportation_-_english_1.pdf. Accessed 14 June 2018.

Heesch, Kristiann C., Shannon Sahlqvist, and Jan Garrard. 2012. "Gender differences in recreational and transport cycling: A cross-sectional mixed-methods comparison of cycling patterns, motivators, and constraints." In International Journal of Behavioral Nutrition and Physical Activity 9: 106. https://doi.org/10.1186/ 1479-5868-9-106.

Hodgson, Frances. 2012. "Everyday connectivity: equity, technologies, competencies and walking". In Journal of Transport Geography 21: 17-23. https://doi.org/10. 1016/j.jtrangeo.2011.11.001

McGuckin, Nancy, and Yukiko Nakamoto. 2004. "Differences in trip chaining by men and women." In Conference Proceedings 35: Research on Women's Issues in Transportation, Volume 2: Technical papers, 49-45. http://onlinepubs.trb.org/ onlinepubs/conf/CP35v2.pdf. Accessed 27 March 2020.

Peters, Deike. 2013. "Gender and sustainable urban mobility. Official thematic study for the 2013 UN Habitat Global Report on Human Settlements." https:// unhabitat.org/wp-content/uploads/2013/06/GRHS.2013.Thematic.Gender.pdf. Accessed 19 March 2020.

Pickup, Laurie, Oriol Biosca, Laurent Franckx, Herman Konings, Inge Mayeres, Pnina Plaut et al. 2015. "MIND-SETS: A new vision on European mobility." Deliverable 2.1A of the MIND-SETS project. European Commission Directorate General for Research. http://www.mind-sets.eu/wordpress/wp-content/ uploads/2015/11/D2.1.a_final.pdf. Accessed 13 June 2018.

Samek Lodovici, Manuela, and Nicoletta Torchio. 2015. "Social inclusion in EU public transport." Policy Department B: Structural and Cohesion Policies European Parliament. Brussels. http://www.europarl.europa.eu/RegData/etudes/ STUD/2015/540351/IPOL_STU(2015)540351_EN.pdf. Accessed 13 June 2018.

SARTRE. 2012. "European road users' Risk perception and mobility." The SARTRE 4 Survey, Report to the European Commission. Champs-sur-Marne: IFSTTAR.

Schwanen, Tim. 2011. "Car use and gender. The case of dual-earner families in Utrecht, The Netherlands." In Auto Motives. Understanding Car Use Behaviours, 
edited by Karen Lucas, Evelyn Blumenberg, Rachel Weinberger, 151-171. Oxford: Emerald Group Publishing Limited.

Sheller, Mimi. 2008. "Gendered mobilities. Epilogue.” In Gendered Mobilities, edited by Tanu P. Uteng and Tim Cresswell, 257-265. Aldershot: Ashgate.

Stokes, Gordon. 2012. "Has car use per person peaked? Age, gender and car use." Presentation to Transport Statistics User Group. London. April 2012. http://www. gordonstokes.co.uk/transport/peak_car_2012.pdf. Accessed 19 March 2020.

Su, Fengming, and Michael G. H. Bell. 2012. "Travel differences by gender for older people in London." In Research in Transportation Economics 34, no. 1, 35-38. https://doi.org/10.1016/j.retrec.2011.12.011.

Tilley, Sara, and Donald Houston. 2016. "The gender turnaround. Young women now travelling more than young men.” In Journal of Transport Geography 54, 349-358. https://doi.org/10.1016/j.jtrangeo.2016.06.022.

Transport for London. 2014. "Understanding the travel needs of London's diverse communities. A summary of existing research." http://content.tfl.gov.uk/ understanding-the-travel-needs-of-london-diverse-communities.pdf. Accessed 13 June 2018 .

World Economic Forum. 2017. "The global gender gap report 2017.” World Economic Forum. Geneva. www.weforum.org. Accessed 14 June 2018. 